\title{
ETHOS, DECORO, LIBERDADE \\ NOTAS SOBRE OS REGIMES DE IDENTIFICAÇÃO DAS ARTES NA OBRA DE JACQUES RANCIÈRE
}

\author{
EDUARDO PELLEJERO \\ Professor de Filosofia da UFRN. Doutor em Filosofia. E-mail: edupellejero@gmail.com. \\ http://lattes.cnpq.br/1224372202417906
}

Artigo submetido em Novembro/2016 e aceito em Dezembro/2016

\section{RESUMO}

Numa das revisitações críticas mais importantes das últimas décadas, a obra de Jacques Rancière propõe uma redefinição do modo de identificação da arte que domina a nossa época. Essa problematização das categorias históricas tradicionais (modernismo, modernidade, pósmodernidade), em ordem a repensar as relações entre as práticas artísticas e as práticas políticas, implica uma reconsideração das definições da arte e da política, assim como das tarefas da crítica. $O$ presente ensaio pretende oferecer uma aproximação aos conceitos em jogo nessa empresa.

Palavras-chave: Rancière. Estética. Arte. Regimes de identificação.

\section{RESUMEN}

En una de las revisiones crtíticas más importantes de las últimas décadas, la obra de Jacques Rancière propone una redefinición del modo de identificación del arte que domina nuestra época. Esa problematización de las categorías históricas tradicionales (modernismo, modernidad, posmodernidad), en orden a repensar las relaciones entre las prácticas artísticas y las prácticas políticas, implica una reconsideración de las definiciones de arte y política, así como de las tareas de la crítica. El presente ensayo pretende ofrecer una aproximación a los conceptos en juego en esa empresa.

Palabras clave: Rancière. Estética. Arte. Regímenes de identificación. 
When the flush of a new-born sun fell first on Eden's green and gold, Our father Adam sat under the Tree and scratched with a stick in the mould; And the first rude sketch that the world had seen was joy to his mighty heart, Till the Devil whispered behind the leaves, "It's pretty, but is it Art?"

Rudyard Kipling

Procurando restabelecer as condições de inteligibilidade de um debate cuja importância não é possível colocar em questão, Jacques Rancière tenta pensar claramente aquilo que, sob a noção de modernidade estética, é pensado de forma confusa. Essa problematização das categorias históricas tradicionais (modernismo, modernidade, pósmodernidade), em ordem a repensar as relações entre as práticas artísticas e as práticas políticas, implica uma reconsideração dos conceitos de arte e política, assim como das tarefas da crítica. Tal é o sentido das suas análises estéticas em termos de regimes de identificação das artes, isto é, em termos de tipos específicos de "vínculo entre modos de produção de obras ou práticas, formas de visibilidade de ditas práticas e modos de conceituação de uns e outros" (Rancière, 2009, p. 27-28) ${ }^{1}$.

A partir dessa perspectiva, Rancière distingue três grandes regimes de identificação: um regime ético das imagens, um regime poético das artes e um regime estético da arte ${ }^{2}$. $A$ divisão tripartite permite seguramente uma melhor inteligência do que se encontra em jogo nas diferentes configurações da partilha do sensível. Nomeadamente, nesse quadro, a caraterização do regime estético da arte constitui uma tentativa de redefinir o modo em que tendemos a fazer, ver e pensar a arte nos nossos dias, levantando uma série de questões que perpassam a história da política e da arte, mas também a história da crítica, da filosofia e da educação, enquanto planos sobre os quais está em jogo (ainda) o sonho da emancipação universal.

O primeiro dos regimes de identificação das artes caraterizado por Rancière é o regime ético das imagens, e a primeira coisa que devemos notar é que, paradoxalmente, nele, a arte não é identificada como tal.

\footnotetext{
1 "Fundar o edifício da arte quer dizer definir um determinado regime de identificação da arte. Não há arte, evidentemente, sem um regime de percepção e de pensamento que permita distinguir as suas formas como formas comuns. Um regime de identificação da arte é aquele que põe determinadas práticas em relação com formas de visibilidade e modos de inteligibilidade específicos. A mesma estátua da deusa pode ser arte ou não sê-lo, ou sê-lo de uma forma diferente segundo o regime de identificação com o qual se a julgue." (Rancière, 2005, p. 18)

2 Sob esse horizonte de apostas estéticas e políticas, a definição operativa dos regimes ético e poético, em relação aos quais se destaca o regime estético da arte, não atinge sempre o grau de definição que permitiria uma confrontação produtiva com outras formas de abordar e problematizar as categorias epocais em questão e, mais importante, a caraterização do nosso próprio tempo. Obras consideráveis como a de Erich Auerbach (pontualmente considerada por Rancière em Os nomes da história e Aisthesis) ou a de Hans Belting, podem enriquecer consideravelmente a revisão rancieriana, e nessa mesma medida ajudar-nos na redefinição do espaço estético, enquanto palco comum para os modos de articulação do comum e as formas de intervenção artística.
} 
Rancière coloca arte entre aspas em algumas ocasiões quando se refere a este regime: escreve "a arte", sem dar conta do significado desse artifício tipográfico, que continuará a assombrar a sua caraterização do regime poético das artes. Podemos deduzir, em todo o caso, que o ênfase não se refere à ignorância do ofício de produzir esculturas ou afrescos, vasos ou tragédias, mas de uma subordinação desses afazeres à questão das imagens ${ }^{3}$.

O certo é que Rancière afirma um regime de produção, contemplação e conceituação que propriamente não reconhece uma identidade diferenciada à arte (às práticas artísticas ou à experiência estética) nem aos seus produtos (obras de arte). Isso quer dizer que as histórias da poesia épica, as figuras da escultura ou da pintura, as cenas da tragédia ou as alusões da música não possuem um estatuto diferenciado, não são nem feitas nem vistas nem pensadas de forma autónoma, mas se encontram subordinadas à questão das imagens (especialmente, das imagens religiosas). Rancière precisa:

Existe um tipo de seres, as imagens, que são objeto de uma dupla questão: a da sua origem e, em consequência, o seu conteúdo de verdade; e a do seu destino: os usos aos que servem e os efeitos que induzem. Se desprende desse regime a questão das imagens da divindade, do direito ou da proibição de produzi-las, do estatuto e da significação daquelas que são produzidas. (Rancière, 2009, p. 28)

Rancière é claro ao tomar distância de outros autores que, em ordem a definir o regime de identificação da arte que é o nosso, propõem uma ruptura com o estatuto religioso das obras. No caso de Benjamin, por exemplo, Rancière coloca em causa a assimilação da inscrição ritual da arte no passado e a determinação aurática da arte; denuncia, concretamente, um paralogismo na dedução do próprio da pintura a partir da teologia do ícone, assim como na ligação do valor ritual da imagem ao valor de unicidade da obra de arte. Para Rancière, a função icónica da arte e o valor de culto das imagens pertencem a um regime que exclui a especificidade da arte e a unicidade das obras enquanto tais ${ }^{4}$, e a sua confusão implica uma ambiguidade de fundo, que sustenta discursos de signos tão opostos como os que celebram a desmistificação moderna da arte ou os que dotam a obra e o seu espaço de exposição dos valores sagrados da representação do invisível ${ }^{5}$.

\footnotetext{
${ }^{3}$ Mesmo sendo mais provável que se trate de uma consideração retrospectiva ou, inclusive, historicista: como se dissesse, no fundo, que 'a arte', tal como é identificada no muito especial regime que é o nosso, não era reconhecida como tal no regime ético. Voltaremos a isso, mas deixemos nota da subordinação da caraterização dos regimes que precedem o regime estético da arte a este último (espécie de construção historiográfica associada à proposta de redefinição da época que é a nossa além das categorias de modernidade, pósmodernidade, etc.).

4 "A retração de um é necessária para a emergência do outro. Não implica que o segundo seja a forma transformada do primeiro." (Rancière 2009, p. 29)

${ }^{5}$ Para Rancière também é duvidoso que seja possível deduzir as propriedades estéticas e políticas de uma arte a partir das suas propriedades técnicas; pelo contrário, acredita que a mudança associada à fotografia e ao cinema depende de um novo regime de identificação das artes que, ao mesmo tempo, confere visibilidade às
}

Dialektiké, v. 2, 2016. p. 19-35 
Ràncière é menos claro (faz caso omisso) na hora de assinalar pontos em comum com alguns estudos especializados que tentaram determinar essa espécie de (pre)história das imagens. Penso, por exemplo, na aproximação às imagens antes da era da arte que Hans Belting propõe faz mais de trinta anos.

Belting explora um regime no qual a perspectiva sobre as imagens, longe de ser uma perspectiva artística ou estética, é uma perspectiva definidamente religiosa, sendo objeto de numerosas polémicas (não apenas teológicas). Segundo Belting, encontramo-nos tão profundamente influenciados pela era da arte que nos é difícil imaginar a era antes da arte; nos é difícil compreender que as imagens fossem alguma vez "não só algo para olhar, mas algo em que acreditar" (Belting, 2003, p. 15):

Ao venerar a imagem praticava-se um exercício de memória ritual. Frequentemente permitia-se o acesso a uma imagem quando havia ocasião oficial para honrá-la; não era possível contemplá-la à vontade, mas se a aclamava exclusivamente num ato de solidariedade com a comunidade, de acordo com o programa estabelecido para uma data determinada. Essa prática identifica-se como culto. (Belting, 2003, p. 15) ${ }^{6}$

A luz que lança o trabalho de Belting sobre a definição do regime ético das imagens proposto por Rancière nos permite compreender muito melhor o sentido em que deve ler-se a impossibilidade que experimenta "a arte" para individualizar-se, submetida à questão das imagens, pela sua vez subordinada ao ethos das comunidades tradicionais.

Mas o trabalho de Belting é ainda mais interessante (para a leitura de Rancière) quando considera a perda do poder das imagens durante a Reforma, na medida em que explica essa mudança a partir de duas formas de partilha do sensível: por um lado, as imagens perdem o seu poder durante a reforma perante os textos escritos e, por outro, as interpretações dos predicadores ganham espaço, como correlato de uma tentativa de emancipar-se das velhas instituições eclesiásticas, propondo um novo recorte do espaço e do tempo, das competências para ler e interpretar os textos sagrados, cujo modelo seria a pequena comunidade conformada pelo predicador e a sua congregação (ou, inclusive, pela família reunida em oração).

A atitude liberal de Lutero ainda deixava espaço para as imagens, mas estas eram utilizadas com propósitos didáticos, para reforçar a revelação da palavra. Essa limitação despojou as imagens da sua aura, que era

massas e permite que as artes mecânicas sejam vistas como tais (Rancière 2009, p. 45-46). A revolução técnica vem depois da revolução estética, essencialmente ligada à literatura do século XIX.

6 "A imagem cumpria múltiplas funções; além de definir o santo e honrá-lo no culto, também exercia uma função relacionada com o lugar onde residia. A presença do santo local estava, por assim dizer, condensada numa imagem corpórea, que tinha uma existência física, como um painel ou uma estátua, e uma aparência especial, como modelo de imagem, aparência que a distinguia das imagens do mesmo santo em diferentes lugares." (Belting, 2003, p. 16) 
precondição do seu culto. Daí seguia-se que não poderiam nem deveriam representar nenhuma instituição. (Belting, 2003, p. 16) ${ }^{7}$

Evidentemente, o esquema historiográfico proposto por Belting não coincide ponto por ponto com o de Rancière, nomeadamente na hora de redefinir o regime em que nós identificamos a arte - associado, para Belting, à inscrição da arte na esfera do artista, que assume o controle da imagem como prova da sua arte, abrindo um espaço para um novo uso (diferente) das imagens, sobre o qual o artista e o espectador podem por-se de acordo: um espaço propriamente artístico, onde a forma e o conteúdo renunciam ao seu significado sem mediação, em favor do significado mediado da experiência estética e da argumentação encoberta. Mas a análise detalhada dos seus exemplos oferece um corpo adequado à caraterização do regime ético das imagens, que Rancière nos propõe ler, mais que nada, de forma oblíqua, na incapacidade de Platão para separar claramente a arte, distinguir as práticas artísticas de outras práticas e considerar algum tipo de autonomia dessas práticas em relação ao ethos da comunidade.

Também se desprende daí toda a polémica platónica contra os simulacros da pintura, o poema e a cena. Platão não submete, como costuma dizer-se, a arte à política. Essa distinção carece de sentido para ele. Para ele não existe arte, mas só artes, maneiras de fazer. E é entre elas que traça a linha da divisão: há artes verdadeiras, isto é, saberes fundados na imitação de um modelo com fins definidos, e simulacros de arte que imitam simples aparências. Essas imitações, diferenciadas pela sua origem, são diferenciadas também pelo seu destino: pela forma em que as imagens do poema dão às crianças e aos espectadores cidadãos certa educação e se inscrevem na partilha das ocupações da cidade. (Rancière, 2009, p. 28) ${ }^{8}$

\footnotetext{
7 “Esse processo também se deu no mundo católico, e não só como reação à crítica da Reforma. Na Holanda, a Reforma só se introduziu oficialmente a partir de 1568. Não obstante, a transformação da imagem descrita tinha-se dado há algum tempo atrás. Para conservar as exigências da imagem cultual na era da arte, a Igreja Romana tinha que estabelecer novas atitudes em relação às imagens. Os antigos títulos tendiam agora a ficar reservados às imagens antigas, que consideravam relíquias de uma época já passada. Essas relíquias sempre se conceberam como imagens procedentes dos primeiros períodos do cristianismo e, desse modo, usaram-se como refutação visível do conceito de tradição da Reforma. Nesses casos, deu-se à arte contemporânea a tarefa de fornecer a apresentação efetiva da imagem antiga. Esse foi um importante programa durante a Contrarreforma." (Belting, 2003, p. 18)

${ }^{8}$ Em relação à questão da origem e da verdade das imagens, o trabalho de Belting também poderia servir de mediação para compreender o que está em jogo no regime ético das imagens do ponto de vista do seu funcionamento intrínseco (e não simplesmente da perspectiva da sua apropriação por Platão): “As imagens de Maria, por exemplo, sempre se distinguiam visivelmente entre si, de acordo com as caraterísticas atribuídas às cópias locais. Do mesmo modo, os títulos das antigas imagens são de caráter toponímico: nomeiam o lugar de um culto. Portanto, a conexão entre imagem e culto, como vemos, abarca muitos aspetos. A lembrança evocada pela imagem referia-se tanto à sua própria história como à do seu lugar de origem. Faziam-se cópias com o fim de propagar a veneração da imagem além do seu próprio lugar, mas reforçavam a relação entre o original e a sua própria localidade. Logo, a lembrança ligada ao original era conservada sem divisão. As cópias evocavam o original de uma imagem local famosa, a qual, pela sua vez, evocava os privilégios que adquirira dentro da sua própria localidade (e para ela), ao longo da sua história. Nesse sentido, a imagem e a lembrança convertem-se num aspecto da história oficial. (...) As lendas que rodeavam as origens de imagens famosas ajudavam a esclarecer o valor da lembrança que adquiriram ao longo da sua história. Essas lendas referiam-se a
} 
Num artigo dedicado a repensar as questões que levanta a leitura rancièrana de Schiller, Antonio Rivera (2010, p. 225) propõe outro paralelo produtivo, esta vez com o Pequeno tratado de inestética, de Alan Badiou, propondo uma proximidade entre os regimes distinguidos por Rancière e os esquemas propostos por Badiou - didático, clássico e romântico -, sobretudo no que se refere aos dois primeiros. A partir dessa perspectiva, por exemplo, as questões levantadas por Badiou em torno ao caráter - intrínseco ou extrínseco - da verdade da obra de arte, ou à sua irredutibilidade em relação às verdades da ciência ou da política, contribuem para que as definições de Rancière (sobre o regime ético no primeiro caso, e sobre o regime poético no segundo) ganhem alcance e problematicidade.

Uma das maiores diferenças entre o recorte historiográfico proposto por Rancière e o proposto por Belting passa pela posição clássica adotada por este último na hora de definir o regime de identificação das artes que é o nosso. Ainda que Belting reconheça diversas formas de partilha do sensível num mesmo regime de identificação das artes, a representação de temas humanísticos e a procura da beleza como determinantes deste novo regime, distancia-o claramente de Rancière (isso e o fato de que Belting relativize as rupturas nos regimes de identificação, deixando em aberto a possibilidade de um nível metafísico de identificação ${ }^{9}$.

De fato, Rancière propõe um regime de identificação que comportaria um passo intermédio entre o regime ético das imagens e o regime que determina a forma em que nós fazemos, vemos e pensamos a arte: trata-se do regime poético das artes. Segundo Rancière, esse regime praticava efetivamente - no seio das formas de fazer - a distinção das artes miméticas (isto é, as formas de fazer que procedem por representação, tornando-as solidárias de um regime de produção que se subtrai ao ethos da comunidade, às questões do uso, da origem e da verdade das imagens.

Denomino esse regime como poético, enquanto que identifica as artes isso que a época clássica denominaria as "belas artes" - no seio de uma classificação das maneiras de fazer, e define em consequência maneiras de fazer as coisas bem e de apreciar as imitações. $\underline{O}$ denomino representativo, enquanto é a noção de representação ou de mimese que organiza essas maneiras de fazer, ver e julgar. Mas, insisto, a mimese não é a lei que submete as artes à semelhança. É em primeiro lugar a vaza na distribuição das maneiras de fazer e das ocupações sociais que tornam visíveis as artes. Não é um procedimento da arte, mas um regime de visibilidade das artes. (Rancière, 2009, p. 31)

Rancière atribuí a Aristóteles a paternidade desse regime de visibilidade das artes que assegura a autonomia às artes, articulando-as numa ordem geral de maneiras de fazer e

algo mais do que às circunstâncias históricas que garantiam a aparência autêntica da pessoa retratada. O mito da origem também garantia a importância de uma imagem particular, que se deduzia da sua idade (ou da sua origem sobrenatural)." (Belting, 2003, p. 16)

9 "Não há uma espécie de ruptura histórica, na qual a humanidade mude tanto que fique irreconhecível." (Belting, 2003, p. 18) 
ocupações, de competências para produzir e lugares para contemplar. Na Poética encontramos uma série de definições - ao mesmo tempo descritivas e normativas - que abrem uma distância crítica entre a ordem das práticas miméticas e o resto das práticas humanas: a ideia de correção da política já não sobredetermina a ideia de correção poética (Aristóteles, 2007, 1460b).

Mais especificamente, os produtos das artes miméticas já não se deixam traduzir adequadamente pela dialética do modelo e da cópia, passam a ser feitos, vistos e pensados como uma representação cujo valor está dado pela adequação às regras de composição e execução da forma de arte à que pertencem, à poética da qual se reclamam (para ter lugar $)^{10}$. Deslocada sobre o plano da poética, a questão das imagens é transfigurada; a partir de aqui cada objeto exigirá a sua forma de representação adequada, cada forma de representação pressuporá uma delimitação dos seus objetos (e das suas formas de tratálos). Assim, por exemplo, Sófocles e Homero, tragédia e poesia épica, inclusive coincidindo no objeto de representação (homens virtuosos), diferem no modo, no meio, na extensão, etc., dependendo de poéticas diferentes, isto é, de formas de funcionamento e de legitimidade incomensuráveis (Aristóteles, 2007, 1448a). Podemos deduzir, apesar da forma fragmentária em que recebemos a Poética, que existe uma série de diferenças poéticas similares entre a comedia e a tragédia, entre a tragédia e a história, entre o naturalismo de Empédocles e a épica de Homero, e assim por diante ${ }^{11}$.

O certo é que cada arte implica uma poética, isto é, um espaço de legitimidade próprio e, correlativamente, formas de funcionamento associadas tanto ao nível do valor de verdade como do efeito moral das suas representações (exigindo ao mesmo tempo competências especiais para produzi-las e contemplá-las). Nesse sentido, por exemplo, o elevado caráter das ações representadas, a verossimilhança da trama e a catarse propiciada sobre os espetadores são os vectores que articulam o espaço reservado à tragédia. Logo, as censuras que encontramos em Aristóteles são de uma natureza incomensurável com as censuras platónicas que encontrávamos em República. O seu caráter é estritamente poético. Aristóteles as classifica segundo cinco espécies: 1) coisas impossíveis, 2) irracionais, 3) impróprias ao que é correto em relação à arte, 4) contraditórias ao que é correção em relação à arte, 5) contrárias ao que é correção em relação à arte.

Rancière assinala que essas divisões entre o representável e o irrepresentável, essas distinções de gêneros em função dos objetos representados e dos princípios próprios a cada forma poética, dão lugar ao novo regime de identificação. Legislam a atividade poética e asseguram o seu funcionamento, definindo "as condições segundo as quais as imitações podem ser reconhecidas como pertencentes propriamente a uma arte e apreciadas, no seu entorno, como boas ou más, adequadas ou inadequadas" (Rancière, 2009, p. 31).

\footnotetext{
10 "Quando, por acaso, não se viu anteriormente o objeto representado, não é a imitação que causa prazer, mas sim a execução, a cor ou qualquer outro motivo do gênero." (Aristóteles, 2007, 1448b)

11 Por exemplo, "a tragédia se distingue da comédia neste aspecto: esta quer representar os homens inferiores, aquela superiores aos da realidade" (Aristóteles, 2007, 1448a); "nada há de comum entre Homero e Empédocles a não ser o metro; por isso será justo chamar a um poeta e a outro naturalista, em vez de poeta" (Aristóteles, 2007, 1447b).
} 
Rancière resalta também que, ao mesmo tempo, o regime poético das artes estabelece uma ordem hierárquica entre as artes, que não se esgota no terreno poético, mas encontra ecos ao nível das ocupações políticas e sociais:

o primado representativo da ação sobre as personagens ou da narração sobre a descrição, a hierarquia dos gêneros segundo a dignidade dos seus temas, e inclusive o primado da arte da palavra, da palavra em ato, entram em analogia com toda uma visão hierárquica da comunidade (Rancière, 2009, p. 32).

A preferência aristotélica da tragédia sobre a epopeia (ou da tragédia sobre a história) dificilmente dá conta de semelhante dedução, mas a verdade é que a tradição das artes poéticas que tem a sua origem em Aristóteles, não menos que a estruturação das mesmas em gêneros claramente diferenciados, ilustram de diversas formas o sentido do apontado por Rancière.

Sirva como exemplo a seguinte passagem da Epistula ad Pisones de Horácio (texto que retoma de forma ímpar a tradição da poética aristotélica, inclusive se o seu tom é outro, e se a sua perspectiva confunde com a da criação). Horácio recomenda o estudo dos gregos, condena a mediocridade, aconselha a verossimilhança, mas o que nos interessa aqui é a sua apaixonada defensa dos gêneros, da revisão de cada forma de representação ao seu objeto próprio:

Se não posso respeitar o domínio e o tom de cada gênero literário, por que saludar em mim um poeta? Por que falsa modéstia preferir a ignorância ao estudo? A um tema cómico repugna-lhe ser desenvolvido em versos trágicos; a Ceia de Tiestes indigna-se ao ser contada em composições caseiras, dignas, por assim dizer, do soco. Guarde cada gênero o lugar que Ihe corresponde e the assenta. (Horacio, 2005, p. 57) ${ }^{12}$

As hierarquias entre modos de fazer e gêneros artísticos que, segundo Rancière, caracterizam o regime poético das artes, conheceu por outra parte o seu maior auge nas academias europeias a partir do século XVII. Em 1667, por exemplo, André Félibien, no prólogo às Conferências da Academia, propõe uma codificação da pintura clássica segundo os temas pictóricos em jogo (a história, o retrato, a paisagem, as marinas, as flores, os frutos). A pintura histórica (temas religiosos, mitológicos, históricos, literário ou alegóricos) constituía o grande gênero. Em escala decrescente, eram elencadas a pintura de cenas de gênero (representações da vida cotidiana), o retrato, a paisagem, a natureza-morta (simples

\footnotetext{
12 Horacio é, de fato, irredutível no que diz respeito às normas de decoro das artes, aos ritmos apropriados, etc. Isso sendo deixado de lado, a arte converte-se para ele numa mera impostura: "Suponhamos que um pintor decidisse ligar a uma cabeça humana um pescoço de cavalo, juntar membros de diversas procedências e cobrilos de penas variadas, de tal sorte que a figura, de bela mulher acima, acabasse num fedorento peixe negro; ao entrar para ver o quadro, amigos, vocês conseguiriam conter o riso? Acreditem, Pisones, muito parecido com um quadro assim seria um livro onde se fantasiasse sem consistência, como sonhos de doente, de maneira que o pé e a cabeça não combinassem um com o outro." (Horacio, 2005, p. 55)
} 
representações de objetos externos, sem força moral ou imaginação artística). A pintura de gênero, em parte por não responder aos ideais estilísticos da época, em parte pela natureza dos seus temas, era considerada uma arte menor. Ainda em finais do século XVIII, Joshua Reynolds (pintor inglês) colocava no mais alto da hierarquia a pintura histórica (centrada na figura ideal ou idealizada do corpo humano). Alguns artistas muitas vezes impugnavam essas estritas divisões genéricas, dando lugar a novos géneros (grande estilo, paisagem ideal, paisagem histórica, etc.), mas seria necessário esperar os primeiros embates modernistas para colocar em causa a existência de fronteiras poéticas e dar lugar a um novo regime de identificação das artes.

A própria filosofia será durante muito tempo (ao menos até o começo do século XX) espelho fiel desse regime de identificação. É o que encontramos de forma sistemática nas Lições de estética de Hegel, onde a cada momento da história do espírito corresponde um conteúdo adequado e uma figura própria. E é ainda o que encontramos em Schopenhauer, cujas páginas sobre estética compreendem uma rigorosa distinção entre formas de fazer, de acordo às ideias às que se encontram relacionadas (a arquitetura, por exemplo, ocupa o nível inferior, na medida em que apresenta a ideia de matéria bruta e as forças mais básicas da natureza: a gravidade, coesão, rigidez, luz ${ }^{13}$. Cada forma de fazer arte tem o seu lugar, o seu objeto próprio, a sua forma adequada.

Ao contrário do que acontecerá na literatura moderna, já assinalava Auerbach, onde não importa que personagem - independentemente do seu caráter e posição social, seja fabuloso doméstico ou histórico - possa ser tratada pela arte imitativa "de maneira severa, problemática e trágica" (Auerbach, 1996, p. 37), na antiguidade isso era totalmente impossível.

\begin{abstract}
Ainda que nas poesias pastoris e eróticas existam algumas formas intermedias, no conjunto rege a regra da separação de estilos: o que corresponde à realidade vulgar, ao cotidiano, não pode ser apresentado senão na comédia, sem aprofundamentos problemáticos. Tudo isso impõe estreitos limites ao realismo antigo, e se empregamos essa palavra com maior rigor teremos que concordar que assim é excluído qualquer acolhimento sério, na literatura, dos ofícios e classes correntes comerciantes, artesãos, camponeses, escravos -, dos cenários cotidianos casa, oficina, tenda, campo -, numa palavra, do povo e da sua vida. (Auerbach, 1996, p. 37)
\end{abstract}

Limitação, não apenas da estilística, mas também, e mais profundamente, da consciência histórica, que para Auerbach tem por origem o "horror aristocrático perante o devir que se desenvolve nas profundidades, o qual é considerado como vil e orgiástico e carente de lei" (Auerbach, 1996, p. 43).

Ao mesmo tempo, enquanto a literatura moderna desconhece a autoridade da tradição e se dirige a todos ("a não importa quem", dirá Rancière), na antiguidade, à

\footnotetext{
${ }^{13}$ Isso é assim porque os regimes de identificação, tal como definidos por Rancière, não são simplesmente as formas ideológicas sob as quais pensamos a arte de forma acrítica; pelo contrário, constituem as condições de possibilidade (a priori histórico) em virtude das quais as artes são produzidas, vistas e pensadas.
} 
correlação estilística de forma e conteúdo, dentro dos limites de determinada tradição poética, corresponde uma certa concepção da sociedade que assegura o encontro do artista com o seu público. Petronio, por exemplo, "escreve de cima e para o público das classes cultas" (Auerbach, 1996, p. 53) - as regras da tradição poética, dirá Rancière (2009, p. 32), "entram em analogia com toda uma visão hierárquica da comunidade".

Dentro do quadro delineado por Rancière, no regime ético das imagens a arte não é identificada enquanto tal, não conhece autonomia, mas se encontra subordinada à questão das imagens, que concerne ao ethos da coletividade (religiosa, por exemplo), ao direito ou proibição de produzir tais imagens (da divindade, por exemplo), e ao estatuto e significado das imagens que são produzidas (o ícone, por exemplo), enquanto que no regime poético das artes, a arte conquista certa autonomia em relação ao ethos da coletividade, mas para ser imediatamente associada a uma estrita classificação de maneiras de fazer que define a pertinência dos temas, a adequação das formas, as competências para apreciar, etc., em analogia com uma visão hierárquica da comunidade. Será só com o regime estético da arte que finalmente a arte será libertada de toda e qualquer subordinação, não só a valores éticos e religiosos, mas também a regras poéticas e hierárquicas de temas, gêneros e modos de fazer - dando lugar à ideia de que existe a arte em geral ${ }^{14}$. Isto, como veremos, não

${ }^{14}$ Vale a pena notar que, enquanto Rancière identifica essa mudança na revolução que protagoniza a literatura francesa do século XIX, Auerbach remete-se na sua análise aos evangelhos cristãos. Auerbach propõe como exemplo o relato da negação de Pedro (de acordo à redação de Marcos), na qual identifica a ausência de qualquer regra de separação de estilos, começando pela conjunção de atores de extração social particularmente baixa e a mais profunda problematicidade e tragédia do tratamento: "Pedro não é uma figura cénica que sirva só à ilustrativo, como os soldados de Vibuleno e Percenio, caraterizados como simples pilantras e trapaceiros, mas uma imagem do homem, no seu sentido mais elevado, profundo e trágico. (...) Pedro, em cujo testemunho está fundada a narração, era um pescador, da mais simples origem e educação, e as pessoas restantes que intervêm na cena noturna no pátio da casa do grande sacerdote são criadas e não soldados. Pedro é arrancado da amável vulgaridade da sua vida e chamado a desempenhar o papel mais extraordinário" (Auerbach, 1996, p. 47) Auerbach assinala que uma figura de tão humilde procedência, assim como a classe e o cenário do conflito, são incompatíveis com o estilo elevado da literatura clássica antiga (nunca foram escolhidas como assunto principal de uma exposição): "Trata-se de uma ação policial e as suas consequências, na que intervêm pessoas ordinárias do povo, o que pode ser concebível na antiguidade como palhaçada ou comédia. (...) A antiga convenção estilística cai por si, porque a atitude das pessoas afetadas só pode ser descrita com a maior seriedade, uma samaritana ou uma adúltera quaisquer são arrancadas das circunstâncias vultares das suas vidas e colocadas de repente em presença de Jesus, e a reação dessas pessoas no instante reveste-se necessariamente de uma profunda solenidade e frequentemente um caráter trágico. A antiga regra estilística segundo a qual a imitação da realidade, a descrição de episódios correntes, só podia ser cómica (ou em todo o caso idílica) é, portanto, incompatível com a representação de forças históricas, enquanto trata de plasmar concretamente as coisas, porque vê-se obrigada a penetrar nas profundezas da vida cotidiana do povo, e deve levar a sério o que se encontra; e vice-versa, a regra estilística só pode subsistir onde se renuncia a plasmar visivelmente as forças históricas ou não se experimenta a necessidade de fazê-lo." (Auerbach, 1996, p. 48-49). Em resumo, a cena da negação de Pedro não cabe dentro de nenhum gênero antigo (séria demais para a comédia, vulgar demais para a tragédia, insignificante demais para a historiografia), fazendo saltar pelos ares as normas de decoro e de estilo que regravam o que Rancière denominará de regime poético das artes - o autor do Evangelho de Marcos desconhece a tradição poética, e fala de não importa quem, para não importa quem: "o seu relato dirige-se a todos" (Auerbach, 1996p. 53), com toda a seriedade do mundo. Evidentemente, poderia alegar-se que se trata de uma cena isolada. Laísa Roberta Trojaike observa que a caraterização do regime estético da arte não constitui a determinação de um período histórico, e assinala que Rancière reconhece em toda a história da humanidade - apenas se trata de cenas raras, sendo que só a partir de século XIX se tornariam comuns, de acordo com um devir democrático que é para Rancière a essência da sua definição última e do sentido do seu funcionamento (ver: Trojaike, Laísa, As imagens cinematográficas no contexto da política-estética de Jacques Rancière (dissertação de mestrado), Natal, PPGFIL, 2016). 
significa a mera afirmação da autonomia da arte, como parece ser o caso em boa parte das caraterizações da modernidade artística.

Rancière identifica a ruptura que inaugura o regime estético na literatura francesa do século XIX, ou, mais precisamente, na proposição do anónimo como objeto da literatura francesa do século $X I X^{15}$ - não apenas como objeto de um gênero menor, mas da literatura como um todo, incluídas as suas formas mais elevadas. O regime estético da arte surge quando a força de criação individual se identifica com a expressão da vida anónima ${ }^{16}$, quando a voz individual se identifica com a voz coletiva anónima ${ }^{17}$.

O anonimato, tal como aparece na literatura francesa do século XIX - das suas figura tutelares, pelo menos, como Balzac, Hugo e Flaubert -, subverte toda a ordem da representação clássica. Com o tempo, se estenderá à totalidade das práticas artísticas dando lugar ao regime estético da arte.

Que o anónimo seja não só capaz de tornar-se arte, mas também de uma beleza específica, é algo que caracteriza propriamente o regime estético da arte. O regime estético da arte é, mais que nada, a ruína do sistema da representação, isto é, de um sistema no qual a dignidade dos temas comanda a hierarquia dos gêneros da representação (tragédia para os nobres, comédia para a plebe; pintura histórica contra pintura de gênero, etc.). O sistema da representação definia, com os gêneros, as situações e formas de expressão que convinham à baixeza ou elevação do tema. 0 regime estético das artes desfaz essa correlação entre tema e modo de representação. (Rancière, 2009, p. 47)

O anonimato também pode ser pensado sob a figura do mutismo. Segundo Rancière, quando a obra estética deixa de estar ao serviço da ilustração e da glorificação de forças estatais, sociais ou religiosas, converte-se na expressão de certo mutismo (Rancière, 2005, p. 78): primeiro, das figuras às que até então se consagrava (monumentos e pinturas dedicadas à glória de Deus, dos príncipes, dos nobres e dos ricos), as quais, recluídas nos flamantes museus, já não dizem nada (há uma ruptura com a tradição da sua representação); e, a seguir, das figuras que até então não foram ouvidas, inclusive quando pudessem ser muito barulhentas, e não deixassem de gesticular, de tentar fazer-se ouvir

\footnotetext{
${ }^{15}$ Assim como Rancière entra numa polémica com as determinações da modernidade artística em termos de conquista da autonomia da arte, também marca distâncias com as interpretações que, na senda de Benjamin, identificam a ruptura com o surgimento da fotografia e do cinema - e, em geral, com as potencialidades da reprodutibilidade técnica.

${ }^{16}$ Isto não quer dizer que exista uma equivalência entre anonimato político e anonimato estético. No caso de Flaubert, por exemplo, a sua literatura faz jogar um processo de des-subjetivação que se opõe a qualquer processo de subjetivação dos anónimos - daí a sua afirmação de que lhe interessam menos os mendigos que os piolhos que os devoram. O plano de consistência das formas de individuação estética é o resultado em Flaubert da implosão do plano de consistência onde os sujeitos políticos definem-se destacando o contorno dos objetos comuns.
}

${ }^{17} \mathrm{O}$ próprio conceito de gênio expressa essa identidade dos contrários. 
(assiste-se à emergência de um novo sujeito, de um novo tema, que está associado à proliferação da pintura de gênero) ${ }^{18}$.

O mutismo implica, nesse sentido, a igualação de todas as vozes, das que até então se faziam ouvir e das que não, das que se considerava que tinham algo para dizer e das que pareciam estar privadas da palavra. Por tudo isso, a revolução que traz o regime estético da arte é, mais que nada, "a glória de não importa quem" (Rancière, 2009, p. 48) ${ }^{19}$. Como assinalávamos acima, Auerbach propunha uma demarcação similar para dar conta da transgressão do regime representativo das artes, ainda quando oferecesse um exemplo extemporâneo (que, até onde sei, Rancière não comenta em nenhuma das suas obras).

Fazendo da prosa da vida cotidiana o seu objeto por excelência, a arte se desobriga de qualquer regra específica, de qualquer hierarquia de temas, gêneros e artes, forçando o colapso das barreiras genéricas e as normas de decoro do classicismo ${ }^{20}$.

Pelo mesmo gesto que afirma a absoluta singularidade da arte, contudo, destruirá todo e qualquer critério pragmático para determinar essa singularidade; isso quer dizer que fundará a autonomia da arte ao mesmo tempo em que identificará as suas formas com as formas através das quais a vida se forma a si própria, admitindo uma forma de heteronomia. Noutras palavras, a singularidade do regime estético da arte não se confunde para Rancière com a simples afirmação da autonomia da arte. Autonomia e heteronomia encontram-se indissoluvelmente ligadas no regime estético (Rancière, 2011, p. 3) e não dizem respeito

\footnotetext{
${ }^{18}$ Ao mesmo tempo, como no caso de Flaubert, a desaparecimento total do autor, a anulação da sua voz e do seu estilo, de todas as marcas da subjetividade-autor. Implica a quase indiscernibilidade da sua escrita com a língua comum, a língua das vidas silenciosas. O livro sobre nada elabora uma relação paradoxal com os anónimos que constituem o tema dos seus livros. A vida fictícia desses anónimos expressa-se a nesse processo de subjetivação estética.
}

19 O anónimo não é uma substância mas um processo de distanciamento colocado em questão permanentemente. "É uma relação de três termos, de três anonimatos: o anonimato ordinário de uma condição social, o devir-anónimo de uma subjetivação política, o devir-anónimo caraterístico de um modo de representação artística. (...) Pensar a relação entre estética da política e política da estética, consiste em pensar a relação entre a subjetivação política do anónimo com o devir-anónimo caraterístico da estética." (Rancière, 2005, p. 77) "Não há nenhuma fórmula de resolução dessa tensão que coloque diretamente a força estética anónima ao serviço da força coletiva dos anônimo; o espaço da arte vale a pena pela possibilidade que outorga ao sujeito anónimo da experiência estética, o visitante, um indivíduo qualquer que se move entre vários anonimatos, aquele que nunca sabe exatamente o que é o que vem procurar nesse lugar e de quem os administradores do lugar não saberão o que é que encontrou exatamente. A força igualitária do 'estado estético' está ligada como sempre à constituição de uma forma de 'ociosidade', a uma ruptura da relação entre os fins e os meios que dá lugar ao jogo. A lógica consensual é a lógica do direcionamento, isto é, da identificação dos anónimos, da sua estratificação em públicos específicos, portadores de demandas culturais diferenciadas. O risco de pensar a democracia estética sobre esse modelo é permanente: abertura do interior para o exterior, adaptação aos públicos e às culturas. É necessário opor a essa divisão um metamorfismo que utilize a extraterritorialidade estética para pôr no lugar dos territórios definidos pela divisão consensual o jogo entre as forças disjuntivas do anónimo." (Rancière, 2005, p. 82)

${ }^{20}$ A arte abre-se assim a uma distribuição do sensível e a uma configuração da experiência estética que já não pressupõe forma alguma de sobre-determinação, oferecendo-se a uma experimentação não pautada pela distribuição dos lugares para produzir, ver ou pensar as obras e as práticas artísticas, ligando a obra de arte diretamente ao fora. 
somente (nem quiçá em primeiro lugar) às obras de arte, mas à experiência estética, cujo objeto "não é, ou pelo menos não é apenas, arte" (Rancière, 2011, p. 4) 21.

O que compartilham a experiência e o seu objeto no regime estético da arte é um sensorium comum específico ${ }^{22}$, "um sensorium diferente do da dominação". A liberdade que entra em jogo na experiência estética - e que reflete a ociosidade da imagem da deusa (Juno Ludovisi) - é uma liberdade que não oprime nenhuma realidade existente, uma liberdade não opressiva, uma liberdade sem poder (Rancière, 2010, p. 97). Nesse modo de ser sensível comum aos produtos da arte e à experiência estética, onde se anulam as oposições entre forma e matéria, atividade e passividade, consciência e inconsciência, vontade e nãovontade - suspendendo, portanto, as relações que ordenam habitualmente a experiência sensível (Rancière, 2010, p. 101).

\begin{abstract}
Esse sensível, subtraído às suas conexões ordinárias, é habitado por uma potência heterogênea, a potência de um pensamento que se tornou estranho a si próprio: produto idêntico ao não-produto, saber transformado em não-saber, logos idêntico a um pathos, intenção do inintencional, etc. Essa ideia de um sensível tornado estranho a si próprio, sede de um pensamento que se tornou ele próprio estranho a si próprio, é o núcleo invariável das identificações da arte que configuram originalmente o pensamento estético. (Rancière, 2009, p. 32-33)
\end{abstract}

A experiência estética comporta um estado neutro, uma situação de exceção (2010, p. 92), que implica a dupla suspensão: 1) do poder cognitivo do entendimento que determina os dados sensíveis, e 2) do poder da sensibilidade que impõe os seus objetos ao desejo. "A livre aparência permanece inacessível, indisponível, para o saber, os desejo e os fins do sujeito" (Rancière, 2010, p. 100), mas ao mesmo tempo essa dupla suspensão dá lugar a um jogo livre ${ }^{23}$ que, na relação singular que estabelece com uma aparência livre, "promete um desconhecido estado de igualdade" (Rancière, 2011, p. 6), entre as nossas faculdades, entre o sensível e o inteligível, entre o passivo e o ativo, revogando a oposição entre uma inteligência que ordena e uma materialidade que obedece e resiste, entre a forma livre e a matéria servil - e, por extensão, entre o trabalho manual e o trabalho

\footnotetext{
${ }^{21}$ Rancière atribuí essa caraterização a Schiller, em cuja obra teria lugar a 'cena original' da estética.

22 “A propriedade de ser da arte no regime estético da arte já não está dada por critérios de perfeição técnica, mas pela remissão a certa forma de apreensão sensível." (Rancière, 2005, p. 20)

${ }^{23} \mathrm{O}$ estado neutro próprio da experiência estética, em todo o caso, não implica para Racière que a experiência estética tenha nada de acordo amistoso; pelo contrário, manifesta uma tensão de contrários (que o juízo sobre o belo não resolve): “O sujeito não desfruta serenamente da forma. Encontra-se preso de uma guerra interna na que uma autonomia é conquistada em detrimento da outra, da autonomia formal do entendimento e da vontade. Encontra-se preso devido a que a livre aparência se encontra num estado contraditório que é ao mesmo tempo supremo repouso e suprema agitação. Não é necessária, com efeito, a potência desencadeada pela natureza sublime para pôr o sujeito num estado contraditório de atração e repulsão. A deusa que o atrai com o seu encanto o repele ao mesmo tempo com a sua autossuficiência" (Rancière, 2010, p. 98).
} 
intelectual, entre o povo e as elites ${ }^{24}$, anunciando uma distribuição do sensível mais igualitária, mais livre e mais justa (dissensual) ${ }^{25}$.

O 'livre jogo' das faculdades - intelectual e sensível - não é unicamente uma atividade sem finalidade, é uma atividade equivalente à inatividade, à passividade. Para começar, a 'suspensão' que pratica o jogador, com relação à experiência ordinária, é correlativa a outra suspensão, a suspensão dos seus próprios poderes, frente à aparição de um bloco sensível heterogêneo, um bloco de 'passividade' pura. Em definitiva o 'jogador' está aí para não fazer nada perante essa deusa que nada faz, e a mesma obra do escultor encontra-se presa nesse círculo de uma atividade inativa. (Rancière, 2005, p. 20)

A preservação desse sensorium comum específico constitui para Rancière o essencial da política do regime estético, ora fazendo com que qualquer objeto prosaico devenha poético e repovoe a esfera da experiência estética (Rancière, 2011, p. 18), ora assimilando o sensorium das obras de arte ao sensorium das coisas que não sentem (pedras), convertendo a poesia em algo indiscernível da prosa da vida cotidiana (Rancière, 2011, p. 23). E, mais essencialmente, a política do regime estético joga-se na tensão entre essas duas políticas, que é a tensão entre duas formas de heteronomia: "A vida da arte no regime estético é um vaivém entre esses dois cenários (...). Há certa indecibilidade na política da estética (...). A arte estética promete uma realização política que não pode satisfazer e prosperar nessa ambiguidade." (Rancière, 2011, p. 29)

Em resumo, no regime estético, a arte é arte na medida em que também é algo mais que arte - uma forma (autónoma) de vida ${ }^{26}$. Essas relações podem articular-se seguindo três vectores fundamentais: 1) a arte pode tonar-se vida, 2) a vida pode tornar-se arte, 3) arte e vida podem intercambiar propriedades (isto é, manter a tensão entre um e

\footnotetext{
${ }^{24}$ Rancière identifica essa articulação com a questão política na Crítica da faculdade do juízo, onde "a solução à questão política colocava como condição prévia uma forma de universalidade estética: a constituição de um sensorium comum que permitisse 'a comunicação recíproca das Ideias entre as classes mais cultivadas e mais incultas', e que oferecera o meio-termo entre o refinamento das primeiras e a originalidade das segundas, entre a cultura superior e a simples natureza [KANT, Critique de la faculté de juger, tr. A. Philonenko, Vrin, 1979, p. 177]" (2010 [2004], p. 95).

${ }^{25}$ A aproximação de Ranciére à estética sempre teve como horizonte essa dimensão política, que reconhece em Schiller, em quem a potência da experiência estética encontra-se associada ao valor dessa experiência como princípio de uma comunidade emancipada. "Na análise kantiana, o livre jogo e a aparência livre suspendem o poder da forma sobre a matéria, da inteligência sobre a sensibilidade. Essas proposições filosóficas kantianas, Schiller as traduz, no contexto da Revolução Francesa, em proposições antropológicas e políticas. O poder da 'forma' sobre a 'matéria', é o poder do Estado sobre as massas, é o poder da classe da inteligência sobre a classe da sensação, dos homens da cultura sobre os homens da natureza. Se o 'jogo' e a aparência estéticas fundam uma comunidade nova, é porque são a refutação sensível dessa oposição estre a forma inteligente e a matéria sensível que constitui em definitiva a diferença entre duas humanidades. (...) 0 cenário da revolução estética propõe-se transformar a indecisão estética das relações de domínio em princípio gerador de um mundo sem autoridade." (Rancière, 2005, p. 26)
}

26 "A solidão da obra contém uma promessa de emancipação. Mas o cumprimento da promessa consiste na supressão da arte como realidade aparte, na sua transformação numa forma de vida." (Rancière, 2005, p. 25) 
outro movimento). É esta última determinação que permite a Rancière oferecer um horizonte comum aos diversos movimentos que se envolveram numa das duas primeiras vias (ou nas duas, ao mesmo tempo ou sucessivamente), além dos recortes deficitários em termos de uma modernidade pensada sob a luz particular do romantismo, do modernismo, das vanguardas históricas, etc. E é também esta última determinação a que, contra certos recortes pós-modernistas, permitem a Rancière manter viva a potência emancipadora que carrega o regime estético, restituindo as suas propriedades fundamentais à esfera da experiência estética ${ }^{27}$.

Graças a esse trasfego de fronteiras e de mudanças, do estatuto entre arte e não-arte, a radical originalidade do objeto estético e a ativa apropriação do mundo comum puderam coincidir e constituir-se, entre os paradigmas opostos, como uma terceira via ou uma micropolítica da arte. Foi esse processo o que sustentou as performances da arte crítica e o que nos pode ajudar a compreender as suas transformações e ambiguidades contemporâneas. Se existe uma questão política da arte contemporânea, não é na chave da oposição moderno/pós-moderno. É na análise das metamorfoses que afetam o 'tercio' político, a política fundada sobre o jogo de trocas e deslocamentos entre o mundo da arte e o mundo da não-arte. (Rancière, 2005, p. 39)

Sendo identificada como tal, a arte não conquista uma autonomia longamente perseguida, nem volta a cair sob o jugo de uma heteronomia total. Antes, ocupa uma posição ambígua e elusiva (ansiosa, dizia Harold Rosenberg), onde se entrega a um jogo com elementos e potências heterogêneas dos mais diversos domínios, independentemente de qualquer regra pré-estabelecida, tácita ou explícita (é nisto, apenas, que radica a sua autonomia). Assim, sem normas de decoro que governem a sua atividade nem imposições de tema ou estilo, a arte pode fazer literalmente qualquer coisa (claro que sempre na dúvida de se o que faz é ou não arte, se a sua poesia não se confunde irremediavelmente com a prosa da vida cotidiana, e assim por diante), mas ao mesmo tempo, atuando desse modo, nas trocas entre arte e não-arte que agora regem a experiência estética, o jogo livre entre forma e conteúdo pode chegar a denunciar (com total indiferença em muitos casos) as relações sociais nas que de fato tem lugar, a posição que nessas relações sociais ocupa a arte, etc. ${ }^{28}$ - conjugando, portanto, a exploração do alcance e os limites da arte com a crítica

\footnotetext{
${ }^{27}$ Ao nível das obras, essa restituição reflete-se na afirmação de uma ambiguidade essencial, de uma distância irredutível entre a proposição de uma obra e os efeitos da mesma no espectador. Logo, a obra é objeto de um dissenso sem resolução possível.

28 "A forma esticomitia dada por Brecht a uma discussão sobre couves-flores denunciava os interesses ocultos detrás das grandes palavras. Os bilhetes de ônibus, molas de relojoaria e outros acessórios colados sobre lenços dadaístas ridiculizavam a pretensão de uma arte à margem da vida. As latas de sopa ou as caixas de sabão Brillo introduzidos por Andy Warhol no museu denunciavam as pretensões de isolamento da grande arte. As misturas entre imagens de estrelas de cinema e imagens de guerra realizadas por Wolf Vostell mostravam o lado sombrio do sonho americano. As imagens de homeless projetadas por Krzysztof Wodiczko sobre os monumentos americanos denunciavam a expulsão dos pobres do espaço público; os bocados de cartão colados por Hans Haacke às obras dos museus colocavam em evidência a sua natureza de puros objetos de especulação, etc." (Rancière, 2005, p. 39)
} 
dos mecanismos de dominação social, económica e política. Não há uma verdadeira oposição entre a pureza da arte e a sua politização; há, pelo contrário, uma multiplicidade de formas em que se relacionam ${ }^{29}$ : "o regime estético da arte recusa a priori qualquer oposição entre uma arte autônoma e uma arte heterônoma, uma arte pela arte e uma arte ao serviço da política, uma arte do museu e uma arte da rua". (Rancière, 2005, p. 23)

Nessa medida, Rancière considera exemplar o modo em que a colagem dá corpo a essa zona de indiscernibilidade, realizando o princípio do tercio político estético que assegura a preservação da potência política do regime estético da arte. Com efeito, "antes de misturar pintura, jornais, tela encerada ou mecanismos de relojoaria, [a colagem] mistura a singularidade da experiência estética com o devir-vida da arte e o devir-arte da vida cotidiana", dando lugar habitualmente "a um choque que descobre um mundo oculto por outro: violência capitalista oculta sob o bem-estar do consumo; interesses mercantis e violência de luta de classes detrás da aparência serena da arte, etc." (Rancière, 2005, p. 40)

Nascida do assombro inspirado pelas sobrevivências da cultura clássica, a forma em que fazemos, vemos e pensamos a arte na época que é a nossa, o jogo estético, apesar da sua irredutível liberdade, comporta em última instância para Rancière uma seriedade na qual ecoa não apenas a alegria democrática de obras circulando sem controlo para não importa quem, mas também, sempre e ao mesmo tempo, o alerta que Benjamin fazia pesar sobre todos os monumentos da cultura e as ruinas que o progresso deixa ao seu passo.

\title{
REFERÊNCIAS
}

ARISTÓTELES. Poética. Lisboa: Fundação Calouste Gulbenkian, 2007.

\author{
AUERBACH, Erich. Mimesis. La representación de la realidad en la literatura occidental. \\ México: Fondo de Cultura Económica, 1996.
}

BELTING, Hans. "Semejanza y presencia. Una introducción a las imágenes antes de «la era del arte»". Em: Revista Artes, №. 5, Volumen 3, enero/junio, 2003.

\footnotetext{
29 “Por um lado, a política não é a simples esfera de ação que viria depois da revelação estética do estado de coisas. Tem a sua estética própria: os seus modos de criação dissensuais de cenas e de personagens, de manifestações e de enunciações que se distinguem das criações da arte e se opõem em algumas ocasiões inclusive a elas. Por outro lado, a estética tem a sua política, ou uma tensão entre duas políticas opostas: entre a lógica da arte que se converte em vida ao preço de suprimir-se como arte e a lógica da arte que faz política com a condição expressa de não fazê-la em absoluto. A arte crítica é então uma arte que negoceia a relação entre as duas lógicas estéticas: entre a tensão que empurra a arte para a vida, e a que separa a sensorialidade estética das outras formas de experiência sensível. Deve tomar emprestado às zonas de indistinção entre a arte e as outras esferas as conexões que provocam a inteligibilidade política. E deve tomar emprestado ao isolamento da obra o sentido de heterogeneidade sensível que alimenta as energias políticas da recusa. (...) A combinação dessas duas forças adquire necessariamente a forma de uma ajuste de lógicas heterogéneas." (Rancière, 2005, p. 34)
} 
HORACIO. Epistula ad Pisones. Em: Aristóteles, Horácio, Longino. A poética clássica. São Paulo, Editora Cultrix, 2005.

RANCIÈRE, Jacques. A partilha do sensível. São Paulo, Editora 34, 2009.

A revolução estética e seus resultados. São Paulo: Projeto Revoluções, 2011.

Disponível em: http://www.revolucoes.org.br . "Schiller y la promesa estética". Em: Rivera, A. (ed.). Schiller, arte y política. Murcia: Universidad de Murcia, Servicio de publicaciones, 2010.

Sobre políticas estéticas. Barcelona: Bellaterra, 2005.

RIVERA, Antonio. "La distancia estética. Potencia y límites de la relación entre arte y democracia". Em: Rivera, A. (ed.). Schiller, arte y política. Murcia: Universidad de Murcia, Servicio de publicaciones, 2010. 